\title{
ESCLERODERMIA ASSOCIADA A ATIVIDADE ELÉTRICA MUSCULAR CONTINUA
}

\author{
José ANTonio Levy * \\ EHRENFRIED O. WiTTIG ** \\ Eduardo C. Figueiredo Ferraz ***
}

A elucidação diagnóstica das doenças difusas do tecido conjuntivo (colagenoses) oferece dificuldades ${ }^{1}$, sobretudo pela variabilidade da sintomatologia clínica e pela falta de métodos diagnósticos específicos.

O paciente objeto do presente trabalho estêve internado durante vários meses com o diagnóstico de provável esclerodermia; dentre as entidades cogitadas para o diagnóstico (esclerodermia, dermatomiosite, polimiosite, "stiffman syndrome", doenças do sistema extrapiramidal), pôde-se concluir, pela anamnese, exame clinico e exames laboratoriais, que realmente a hipótese de esclerodermia era a mais aceitável; a dificuldade encontrada para firmar êsse diagnóstico consistiu na atividade muscular contínua em repouso, revelada pela eletromiografia, fenômeno que não haviamos até então observado e para o qual não encontrávamos explicação.

Sòmente meses depois é que tivemos oportunidade de ler trabalho de Isaacs ${ }^{2}$ relatando dois casos semelhantes ao nosso, tendo o autor formulado hipótese explicativa para o fenômeno eletromiográfico, bem como conseguido remissão dêste e da sintomatologia com o emprêgo de hidantoinatos.

\section{OBSERVAÇAO}

A.B., com 15 anos de idade, sexo masculino, branco, brasileiro, internado na Clínica Neurológica em 10-2-1962 (R.G. 246.756). A moléstia iniciou-se há dois anos, com dificuldade na utilizaçāo dos dedos; o processo progrediu, levando os dedos a moderada flexo-adução. Cinco meses após foi operado de adenóides (anestesia local), pois manifestava discreta dificuldade respiratória, tendo melhorado. Há 4 meses o quadro acentuou-se, ocorrendo flexão dos antebraços e moderada rotação interna dos braços, dificuldade para abrir a bôca e dispnéia discreta, mesmo em

Trabalho da Clínica Neurológica (Prof. Adherbal Tolosa) e do Serviço de Fisioterapia do Hospital das Clinicas (Dr. Eduardo Cotrin), da Faculdade de Medicina da Universidade de São Paulo: * Professor Assistente da Clínica Neurológica; ** Bolsista da CAPES; *** Médico Assistente do Serviço de Fisioterapia. 
repouso. As manifestações progrediram, apresentando o paciente, na ocasiăo da internação, grande dificuldade respiratória, disfagia e acentuada hipertonia; foi referida também hipertermia há um mês e emagrecimento. Antecedentes - 0 pai do paciente era epiléptico. O paciente nasceu de parto normal; nega convulsôes. Exame físico - Ausência de pêlos axilares e pubianos; genitais externos pouco desenvolvidos. Pele sêca e lisa. Pressão arterial $120 \times 80 \mathrm{~mm} \mathrm{Hg}$, pulso 90 bat./ min. Tiragem costal e supraclavicular; dispnéia predominantemente inspiratória; elasticidade e expansibilidade torácicas diminuidas; sibilos inspiratórios, cornagem ao nível da laringe. Exame neurológico - Face com pele lisa, distendida e com desaparecimento dos sulcos; bôca entreaberta por elevação do fascículo superior do músculo oro-orbicular (fig. 1); o aspecto geral assemelha-se à fa. cies tetânica ou esclerodérmica. Braços em adução e rotação interna moderada; flexão e leve pronação do antebraço, discreta abdução da mão, flexão acentuada da articulação metacarpo-falângica e discreta das interfalângicas, sendo esta última menos nitida nos indicadores e polegares, onde predominava a flexão da segunda falange (fig. 1): flexão dorsal da articulação metatarso-falângica em todos os artethos. Equilibrio normal. Amplitude dos movimentos articulares diminuida nos membros superiores, conseguindo o paciente movimentá-los muito pouco voluntàriamente, sendo maior a incapacidade nas extremidades distais; essa limitação existia também nos movimentos do tronco; nos membros inferiores, discreta dificuldade na movimentação dos pés, sem limitaçôes; movimentes mandibulares e faciais diminuidos, não sendo possivel separar as arcadas dentárias além de $25 \mathrm{~mm}$. Contraturas de todos os músculos dos membros superiores, mais acentuada nos que determinam a atitude anormal (fig. 1); no tronco, contratura das musculaturas lombar, torácica. e abdominal. Prejudicada a pesquisa da fôrça muscular. Articulações inalteradas. Consistência muscular aumentada, principalmente nos mem-
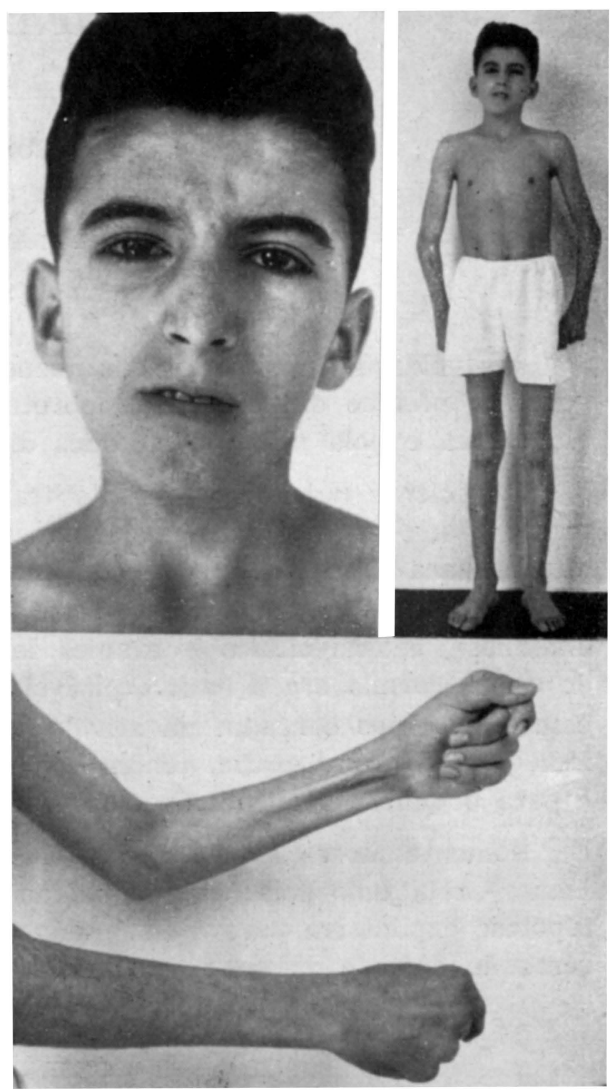

Fig. 1 - Caso AB. Na face: supressão dos sulcos faciais; bôca entreaberta em virtude da contratura do músculo oro-orbiculor. As duas outras fotografias mostram a atitude anormal $e$ as contraturas musculares nos membros superiores. bros superiores e tronco. A palavra é um pouco analasada; a mimica é fixa, sem modificações aprecjáveis da expressão; pequena disfagia para sólidos. Fasciculações por percussão nos músculos deltóides, biceps e suprascapulares. Tremor leve e arritmico das pálpebras superiores. Reflexos mediopubiano e cutâneo plantar normais, estando os demais com a pesquisa prejudicada (não foram obtidos). Reflexos fotomotor e de acomodação normais. Atrofias musculares discretas nos 
membros superiores, mais nitidas nas extremidades distais. Tendões dos punhos, dorso dos pés e região maleolar, salientes. Sensibilidades superficiais e profundas normais.

Exames complementares - Líquido cefalorraqueano, colhido por punção lombar, normal. Reaçôes sorológicas para lues, negativas. Eletroforese das proteinas do sôro: albumina $59,2 \%$, globulinas: $\alpha, 3,5 \% ; \alpha, 5,9 \% ; \beta 6,3 \% ; \gamma 25,1 \%$. Dosagem de cálcio no sôro $12 \mathrm{~g} / 100 \mathrm{ml}$. Dosagem de creatinina no sôro 0,8 g/100 ml. Hemossedimentação $4 \mathrm{~mm}$ na primeira hora (normal). Exame dermatológico com biopsia de pele: quadro de esclerodermia associado a manifestaçōes sistêmicas. Exame otorrinolaringolólógico: à laringoscopia indireta nota-se saliência das pregas aritenóides; esta saliência é simétrica no sentido da luz da faringe; cordas vocais paralisadas e com tendência à rigidez; as vibrações da voz apenas separam por frações de milímetros ambas as cordas; ausência de desvio glótico. Exame reumatológico: quadro sugestivo de afecção difusa do colagênio. Radiografia do tórax: transparência pulmonar aumentada, abaixamento das cúpulas frênicas. Radiografia das màos e punhos: osteoporose do esqueleto das mãos e punhos, particularmente periarticular; deformidade em flexão metacarpofalangeana; espaços articulares conservados; o quadro radiológico não é específico de artrite reumatóide, não se podendo, no entanto, afastar tal possibilidade. Radiografias do intestino delgado: hipotonia generalizada, hipoperistaltismo, alterações funcionais do relêvo da mucosa; trânsito lento; não há sinais de lesão orgânica do intestino delgado. Pesquisa de células LE, negativa. Exame pneumológico: insuficiência respiratória por contração dos músculos torácìcos. Provas funcionais pulmonares: insuficiência pulmonar ventilatória essencialmente obstrutiva; após inalação de ácido cloridrico diluido não se observaram alterações dignas de registro (Dr. Mateus Romeiro Neto). Exame elétrico: exame dificultado pelo espasmo da musculatura; notou-se, no entanto, hipoexcitabilidade galvânica nos músculos triceps e braquiorradiaiss, sobretudo à esquerda; reação dismiotônica nos músculos das mãos.

Exame eletromiográfico - Técnica utilizada: aparelho eletromiógrafo Meditron, modēlo 201-A, eletródio monopolar. O EMG de músculos do membro superior e inferior e da face revelou a presença de descargas de alta freqüência, com 100 a 800 microvolts, que se mantiveram durante todo o exame, embora fôssem feitas diversas manobras para se conseguir relaxamento muscular (fig. 2). Repetimos o

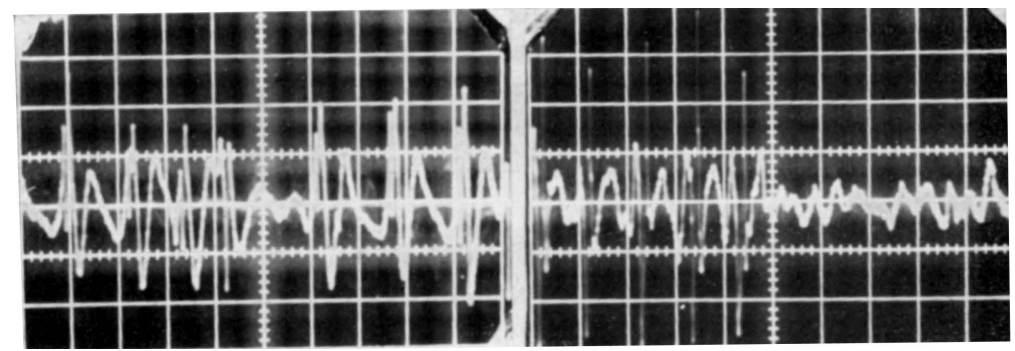

Fig. 2 - Potenciais espontâneos nos músculos tibial anterior direito $e$ extensor dos dedos da mäo direita. Calibração: $10 \mathrm{~ms} / \mathrm{cm}, 100 \mu \mathrm{v} / \mathrm{cm}$.

exame utilizando inicialmente o bloqueio periférico do nervo peroneal comum com novocaina a $2 \%$, o qual produziu ligeira diminuição da atividade elétrica espontânea. Nôvo exame foi feito, com o paciente submetido à anestesia geral pelo Thionembutal, sem modificação da atividade elétrica espontânea. Finalmente, com o paciente sob anestesia geral e com intubação endotraqueal, aplicamos substância curarizante (Taquicurin), obtendo imediata cessação de qualquer atividade elétrica, a qual reapareceu após terminar a ação farmacológica prevista da dose utilizada. 
Reexaminamos o paciente quando se encontrava sob tratamento clinico por difenilidantoina $(300 \mathrm{mg} /$ dia $)$. Verificamos modificação acentuada do quadro eletromiográfico, com diminuição da atividade elétrica espontânea, que se manifestava apenas por algumas descargas de alta frequiência, com intervalos de silêncio elétrico de alguns segundos.

\section{COMENTARIOS}

O caso assemelha-se aos de Isaacs ${ }^{2}$, tanto clínica como eletromiogràficamente.

Em nosso paciente seguimos a mesma orientação de Isaacs: bloqueio anestésico de nervo periférico (peroneal), seguido de anestesia geral, sem que houvesse alteração no traçado. Isto nos sugeriu que as descargas deveriam partir da placa mioneural ou membrana celular; administramos substância curarizante, observando imediato desaparecimento das descargas elétricas, as quais retornaram ao cessar o efeito medicamentoso. Êste fato levou-nos a considerar o fenômeno como tendo origem nas placas mioneurais.

Isaacs foi ainda mais longe: raciocinou que, se o uso de uma substância química bloqueadora da membrana (barbitúrico) nāo fazia desaparecer o fenômeno, seria êste decorrente de alterações nas terminações mioneurais, visto ter cedido com o emprêgo de um agente competidor da placa (curare). Ainda dentro dêste raciocínio, empregou outras substâncias, tais como magnésio, cálcio e quinino, concluindo que as alterações seriam decorrentes de modificações nas terminações neuronais; acreditava, mesmo, que as placas motoras e terminações mioneurais tinham outras funções peculiares afora as conhecidas, sem, entretanto, comentá-las.

O autor comparou êste fenômeno ao das disritmias cerebrais, imaginando que tal situação de estimulação continua estivesse acontecendo nas terminações mioneurais, e utilizou, como tentativa terapêutica, uma substância empregada nestas eventualidades. $\mathrm{Na}$ crise epilética há uma despolarização brusca da célula nervosa pela entrada de sódio na célula, sendo os hidantoinatos capazes de diminuir a concentração de sódio intracelular pelo aumento da retirada ativa dêste íon (bomba de sódio). Os resultados foram surpreendentes, tendo a sintomatologia e o fenômeno eletromiográfico desaparecido em poucos dias.

Em nosso paciente o uso de corticóides levou a razoável melhora clínica mas não eletromiográfica; entretanto, o emprêgo de $300 \mathrm{mg}$ diários de hidantoinato de sódio proporcionou resultados que realmente nos surpreenderam pela sua rapidez, com acentuada melhora clínica e do traçado elétrico anormal em poucos dias.

\section{RESUMO}

E relatado o caso de um paciente do sexo masculino, de 15 anos de idade, que apresentava dificuldade para movimentar os braços e para abrir a bôca, além de dispnéia, evoluindo lentamente há dois anos. O exame neurológico revelou hipertonia em todo o corpo, predominando em alguns grupos musculares que se achavam fortemente contraturados, obrigando o paciente 
a assumir atitudes anormais, impossibilitando-o, ainda, de abrir a bôca e de respirar livremente, dada a grande diminuição da expansibilidade torácica. O exame eletromiográfico revelou a presença de atividade muscular continua, mesmo durante o repouso, caracterizada por descargas de alta freqüência, as quais persistiram após bloqueio anestésico de nervo periférico e após anestesia geral, sòmente sendo eliminados pelo curare. Com o diagnóstico de esclerodermia e de miosite, embora só a primeira dessas moléstias pudesse ser comprovada anátomo-patològicamente, o paciente foi tratado com corticosteróides, tendo havido discreta melhora do quadro clínico, sobretudo em relação aos movimentos respiratórios e à abertura da bôca. Tendo, então, o conhecimento de dois casos semelhantes estudados por Isaacs em 1961, com o nome de sindrome da atividade contínua da fibra muscular, os quais haviam sido curados ccm o uso de hidantoinato de sódio, os autores empregaram esta mesma medicação, tendo verificado, após alguns dias, a diminuição acentuada da atividade anormal pelo exame eletromiográfico.

\section{SUMMARY}

\section{Scleroderma associated with continuous electric muscular activity.}

The case of a 15-year-old male patient, suffering from difficulty in moving his arms and opening his mouth and dyspnea which had been slowly developing for two years, is reported. The neurologic examination revealed diffuse hypertonus, predominating in some muscle groups, compelling the patient to assume abnormal attitudes and making it impossible for him to open his mouth and to breathe freely due to a large decrease in the thoracic expansibility. The electromyographic studies showed continuous muscle activity at rest, characterized by high frequency discharges, which continued after anesthetic blocking of a peripheral nerve and after general anesthesia; these discharges were eliminated only when curare was used. Diagnosis was made of scleroderma and myositis, although only the first one could be confirmed by biopsy; the patient was treated with corticosteroids and a slight improvement was evidenced, specially in regard to breathing movements and mouth opening. Based on the good results reported by Isaacs in two similar cases, the authors used sodium hidantoinate, and thus found a marked decrease of the abnormal electric activity, proved though an electromyographic examination made some days afterwards.

\section{REFERENNCIAS}

1. BEKENY, G.; MASSANYI, L. \& PINTER, J. - vber Polymyositis fibrosa: erfolgreiche Behandlung mittels Steroidhormonen und Operation eines mit schweren Kontrakturen der unteren Extremitäten einhergehenden Fallens. Psychiat. Neurol. (Basel) 144:15-33, 1962. 2. ISAACS, H. - A syndrome of continuous muscle-fiber activity. J. Neurol. Neurosurg. Psychiat., 24:319-325, 1961.

Clínica Neurológica - Faculdade de Medicina da Universidade de São Paulo - Caixa Postal 3461 - São Paulo, SP - Brasil. 